This is the peer reviewed version of the following article: Concordance among diagnostic criteria for metabolic syndrome is inconsistent in Spanish adolescents, European Journal of Clinical Investigation

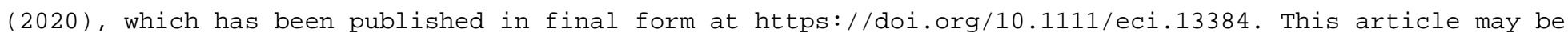
used for non-commercial purposes in accordance with Wiley Terms and Conditions for Self-Archiving.

Article type: Original articles

\title{
CONCORDANCE AMONG DIAGNOSTIC CRITERIA FOR METABOLIC SYNDROME IS INCONSISTENT IN SPANISH ADOLESCENTS
}

Ángel Fernández-Aparicio ${ }^{1}$, Javier S. Perona ${ }^{2 *}$, Jacqueline Schmidt-RioValle ${ }^{1}$, Emilio González-Jiménez ${ }^{1}$

${ }^{1}$ Department of Nursing, University of Granada, Av. Ilustración, 60, 18016, Granada, Spain

${ }^{2}$ Department of Food and Health, Instituto de la Grasa-CSIC, Campus of the University Pablo de Olavide, Building 46, 41013 Seville, Spain.

* Correspondence: perona@ig.csic.es; Tel.: +34-954-611-550

\section{Funding}

This work was supported by funds from Andalusia ERDF 2014-2020 Operative Programme (B-AGR-287-UGR18).

Word count: 3520 


\begin{abstract}
Background: The metabolic syndrome (MetS), although more frequent in adults, is a growing health problem in adolescent population. There are different criteria for the diagnosis, however without a consensus of which is the best to be used in this population. La heterogeneidad existente entre los diferentes criterios diagnósticos hace necesaria la realización de más estudios que analicen el grado de concordancia entre estos criterios. The present study was aimed to evaluate the agreement between different criteria for diagnosis of MetS in adolescents. Materials and methods: A cross-sectional study was performed on 981 adolescents (13.2 \pm 1.2 years) randomly recruited from eighteen schools in south-east Spain. MetS was diagnosed by eight different criteria. Results: The criteria proposed by the IDF showed the highest mean values for $\mathrm{WC}$ and systolic blood pressure in boys and girls with MetS, and the lowest for glucose and triglycerides in boys. Depending on the diagnostic criteria used, the prevalence of MetS cases in boys ranged from $5.5 \%$ to $14.9 \%$, while in girls varied from $3.4 \%$ to $32.6 \%$. Both in boys and girls, the criteria proposed by the IDF was the less concordant with the other suggested criteria, while those proposed by Duncan et al, Rodriguez-Moran et al. and Cruz and Goran, were very concordant among each other. However, in girls, concordance values were not as high as those found for boys. Conclusion: The variability observed in the agreement among the existing criteria suggests the need to validate uniform criteria for the diagnosis of MetS in adolescents.
\end{abstract}

Keywords: Anthropometric indexes; Diagnosis criteria; Metabolic syndrome; Adolescents. 


\section{Introduction}

Metabolic syndrome (MetS) is characterized by a set of three or more metabolic disorders, including abdominal obesity, systemic arterial hypertension, elevated serum triglycerides (TG) and glycemia and low levels of high-density lipoprotein cholesterol (HDLc). ${ }^{1}$ Adolescents that suffer early changes in the components of MetS are associated with a high risk of developing this condition in adulthood, ${ }^{2}$ with an increased risk of developing type 2 diabetes mellitus and cardiovascular diseases (CVD). ${ }^{3}$

On the other hand, the prevalence of MetS in adolescence in many studies is rather divergent, mainly due to the absence of specifically established criteria for its use in non-adult populations. This situation often involves adapting criteria to define MetS in adults to be used in adolescents. ${ }^{4}$ This is the case of the criteria established by the National Cholesterol Education Program - Adult Treatment Panel III, ${ }^{5}$ modified by Cook et al, ${ }^{6}$ Weiss et al, ${ }^{7}$ Duncan et $a{ }^{8}{ }^{8}$ and de Ferranti et al. ${ }^{9}$ The criteria defined by the International Diabetes Federation (IDF) ${ }^{10}$ necessarily include the presence of abdominal obesity for the diagnosis of MetS. On the other hand, Cook et al, ${ }^{6}$ Cruz \& Goran, ${ }^{11}$ de Ferranti et al $^{9}$ and Rodríguez-Moran et $\mathrm{al}^{12}$ consider the existence of three or more impaired components of the Mets as compulsory for the diagnosis, regardless the presence of abdominal obesity. Viner et al, ${ }^{13}$ based on the World Health Organization (WHO) criteria adapted for children by Alberti \& Zimmet, ${ }^{14}$ consider that the existence of four or more impaired components is essential for the diagnosis of MetS.

The main reasons for the heterogeneity in these criteria when adapted for the adolescent population is related to changes in growth and development during childhood and adolescence, which give rise to cut-off points without established values. ${ }^{15,16}$ The divergence is such that some studies have shown a prevalence of MetS ranging from 20 to $300 \%$ in the 
same population depending on the criteria used. ${ }^{17,18}$ The degree of agreement among these criteria is unknown at the moment. Therefore, it is necessary to define a universal criterion for the diagnosis of this condition in adolescents and that facilitates its early screening. ${ }^{19}$ In this sense, the present study aims to contrast the degree of agreement among eight diagnostic criteria to define MetS in boys and girls.

\section{Methods and materials}

\subsection{Study design and sample}

A cross-sectional study was carried out on 981 adolescents (456 boys and 525 girls), $13.2 \pm$ 1.2 years of age (11-16 years old), all of Spanish origin and similar socioeconomic status. The subjects attended 18 high-schools in the provinces of Granada and Almeria (South-East of Spain; 10 public and 8 private). A letter of invitation was sent to the school principals and all centers agreed to participate in the study. Of the 18 schools, two classes per grade of a total of three were randomly selected and invited to participate in the study. To be included in the study, the subjects had to be healthy and not have any type of endocrine dysfunction or physical disorder. All students who did not meet these criteria were not candidates to participate in the study. The flow diagram (Figure 1) summarizes the recruitment process. Reporting of the study conforms to broad EQUATOR guidelines. ${ }^{20}$

The study was previously approved by the Ethics Committee of the University of Granada and also authorized by the school principals. Written informed consent was obtained from all of the parents or legal guardians of the adolescents in accordance with the Declaration of Helsinki. Furthermore, the confidentiality of the personal information was guaranteed by coding the data.

\subsection{Anthropometric measurements}


Each participant underwent an anthropometric evaluation performed by a level 2 anthropometrist certified by the International Society for the Advancement of Kinanthropometry (ISAK), in accordance with the ISAK guidelines. ${ }^{21}$ We performed the anthropometric measurements in the morning after a 12-hour fast and a 24-hour abstention from exercise. La valoración antropométrica se realizó individualmente en un aula provista por cada uno de los colegios, garantizando así la privacidad de los participantes. We measured body weight $(\mathrm{kg})$ twice (with participants wearing no shoes and in light clothes) using a self-calibrating Seca 861 class (III) digital floor scale (Saint Paul, USA) with a precision of up to $100 \mathrm{~g}$. We measured height with a Seca $214 *$ portable stadiometer, asking participants to remove their shoes and stand erect with their backs, buttocks, and heels in continuous contact with the vertical height rod of the stadiometer and head oriented in the Frankfurt plane. We then placed the horizontal headpiece on top of the participants' heads to measure their height. We took height measurements twice to the nearest $0.5 \mathrm{~cm}$. We used the average of the two values for weight and height in the analysis. We calculated body mass index (BMI) as weight divided by height squared $\left(\mathrm{kg} / \mathrm{m}^{2}\right)$. We measured waist circumference (WC) with a Seca automatic rollup measuring tape (precision of $1 \mathrm{~mm}$ ) using the horizontal plane midway between the lowest rib and the upper border of the iliac crest at the end of a normal inspiration/expiration. Also measured were the triceps, biceps, subscapular, and suprailiac skinfolds. The instrument used for this purpose was a Holtain skinfold caliper (Holtain Ltd., Crymych, UK), with an accuracy of $0.1-0.2 \mathrm{~mm}$. The percentage of body fat was based on these skinfold measurements. Previously, the Brook equation was used to calculate body density. ${ }^{22}$ Once the body density value had been obtained, the body fat percentage was determined with the Siri equation. ${ }^{23} \mathrm{~A}$ trained member of the research team collected anthropometric measures in a classroom enabled for this purpose by the principal of each school.

\subsection{Serum biochemical examination}


Blood collection was performed after a previous 12-h fast. At 8:00 AM, $10 \mathrm{~mL}$ of blood was extracted by venipuncture in the antecubital fossa of the right arm with a disposable vacuum blood collection tube. In the 4 hours after the extraction, all samples were centrifuged at 1300 g for 15 minutes (Z400 K, Hermle, Wehingen, Germany). The red blood cells were thus separated and the serum was finally frozen at $-80^{\circ} \mathrm{C}$ for its subsequent analysis. Immediately after collection and before centrifugation, however, we measured glucose concentration using an enzymatic colorimetric method (glucose oxidase-phenol aminophenazone [GOD-PAP] method; Human Diagnostics, Germany) as well as the concentrations of HDL-C, total cholesterol, and triglycerides by means of enzymatic colorimetric methods using an Olympus analyzer. Low-density lipoprotein cholesterol (LDL-C) was estimated using the Friedewald equation $([\mathrm{LDLC}]=[$ Total Cholesterol $]-[\mathrm{HDL}-\mathrm{C}]-([\mathrm{TG}] / 5))$, where $\mathrm{TG}=$ concentration of triglycerides. Serum insulin was determined by radioimmunoanalysis (Insulin Kit; DPC, Los Angeles, EEUU). Insulin resistance was quantified with HOMA (Homeostasis Model Assessment $)^{24}$ by applying the following formula: fasting glucose $(\mathrm{mmol} / \mathrm{L}) \times$ fasting insulin $(\mathrm{mU} / \mathrm{L}) / 22.5$.

\subsection{Blood pressure determination}

We measured blood pressure (BP) levels using a previously calibrated aneroid sphygmomanometer and a Littmann ${ }^{\circledR}$ stethoscope (Saint Paul, USA), following the recommendations for blood pressure measurement of the Subcommittee of Professional and Public Education of the American Heart Association Council on High Blood Pressure Research. ${ }^{25}$ Systolic $\mathrm{BP} \geq 130$ and/or diastolic $\mathrm{BP} \geq 85 \mathrm{~mm} \mathrm{Hg}$ were regarded as a risk factor of MetS. 


\subsection{Diagnostic criteria of metabolic syndrome in adolescents}

Eight different criteria were used to diagnose MetS in the adolescent sample studied: Cook et al, ${ }^{6}$ Weiss et al, ${ }^{7}$ Duncan et al, ${ }^{8}$ de Ferranti et al, ${ }^{9}$ Cruz \& Goran, ${ }^{11}$ Rodríguez-Moran et al ${ }^{12}$ and Viner et al, ${ }^{13}$ as well as the IDF criteria as published by Zimmet et al. ${ }^{10}$ The details of the criteria employed may be consulted in Table Suplemmentary.

\subsection{Statistical analysis}

The Kolmogorov-Smirnov test was used to assess the normality of the distribution. Results were reported as mean $\pm \mathrm{SD}$, except for the number of girls and boys with or without MetS, which was expressed as number. Mean differences between boys and girls were assessed using Student's t-test. Kappa for agreement was calculated for the childhood MetS definitions. Comparisons of means were assessed by ANOVA, followed by Tukey's test. There was no missing data. Statistical analyses were performed using SPSS v24.0 (IBM, Armonk, USA). Statistical significance was defined as $\mathrm{p}<0.05$.

\section{Results}

\subsection{Baseline characteristics of the participants}

Baseline biochemical and anthropometric measurements of participants are shown in Table 1. All measured variables were within normal limits. In general terms, differences between boys and girls were not observed. However, a significant lower WC, body weight and systolic blood pressure (SBP) and a significant higher fat content was found in girls compared to boys.

3.2. Values for components of MetS in subjects with MetS according to different diagnostic criteria. 
Tables 2 shows the values for components of MetS in boys and girls with MetS according to the different diagnostic criteria assessed. In boys, depending on the diagnostic criteria employed, the number of MetS diagnoses ranged from 25 to 68. The highest mean values for WC, HDL-c, SBP and diastolic blood pressure (DBP) were found when the IDF criteria was employed. In contrast, the lowest mean values for WC and SBP were found with the Cook et $\mathrm{al}^{6}$ criteria, and the lowest mean value for HDL-c were found with the Viner et $\mathrm{al}{ }^{13}$ criteria. The criteria proposed by Viner et $\mathrm{al}^{13}$ showed the highest mean levels of glucose and triglycerides. The lowest mean levels for glucose and triglycerides were found with the IDF criteria.

A greater variability in the number of diagnosed girls was observed. In these subjects, the highest mean values for WC, SBP and DBP were found when the IDF criteria was employed. The lowest mean values of WC, SBP and DBP were found when the Cook et $\mathrm{al}^{6}$ criteria were employed. In regard to the biochemical parameters, the highest and the lowest mean values for HDL-c were found when the Cruz and Goran ${ }^{11}$ and Weiss et $\mathrm{al}^{7}$ criteria were employed, respectively. The highest and the lowest mean values for glucose and triglycerides were found when the Weiss et $\mathrm{al}^{7}$ and the Cruz and Goran ${ }^{11}$ criteria were employed. No significant differences were observed in DBP among girls with MetS regardless the criteria used.

\subsection{Prevalence of components of MetS according to the different diagnostic criteria in adolescents with Mets}

Table 3 shows the prevalence of components of MetS in participants with MetS according to the different diagnostic criteria. Depending on the diagnostic criteria used, the prevalence of MetS cases in boys ranged from $5.5 \%$ to $14.9 \%$, while in girls varied from $3.4 \%$ to $32.6 \%$. The highest MetS prevalence in boys was observed with the Duncan et al, ${ }^{8}$ Rodriguez-Moran et $\mathrm{al}^{12}$ and Cruz and Goran ${ }^{11}$ criteria. In girls, the highest MetS prevalence was observed with 
the Cruz and Goran ${ }^{11}$ criteria. Girls had higher MetS prevalence than boys by all definitions except when the IDF, Weiss ${ }^{7}$ and Viner $^{13}$ criteria were employed.

The most frequently MetS component observed in boys with MetS was hypertriglyceridemia by all criteria, except for IDF, Weiss et $\mathrm{al}^{7}$ and Viner et $\mathrm{al}^{13}$ criteria. A greater variability on the most frequent MetS component was observed in girls. Interestingly, in girls, the same prevalence for hyperglycemia and low HDL-c concentration, $6.3 \%$ and $18.1 \%$ respectively, was observed in all diagnostic criteria. In boys, the prevalence for hyperglycemia was $6.8 \%$ by all criteria, while the prevalence for low HDL-c was $18.0 \%$ by all criteria except for those proposed by Weiss et al. ${ }^{7}$

\subsection{Agreement cases of adolescents with MetS according to Kappa after crossing diagnostic} criteria

Tables 4 and 5 show the number of concordant cases of boys and girls with MetS according to Kappa values after crossing the different diagnostic criteria. Both in boys and girls, the criteria proposed by the IDF was the less concordant with the other suggested criteria, while those proposed by Viner et al, ${ }^{13}$ Duncan et al, ${ }^{8}$ Rodriguez-Moran et al ${ }^{12}$ and Cruz and Goran, ${ }^{11}$ were very concordant among each other. In fact, the highest number of MetS diagnosed boys were observed with the criteria by Duncan et al, ${ }^{8}$ Rodriguez-Moran ${ }^{12}$ et al and Cruz and Goran, ${ }^{11}$ showing kappa values above 0.999 (Figure 2). All boys diagnosed of MetS with the criteria published by Weiss et $\mathrm{al}^{7}(\kappa=0.602)$, Viner et $\mathrm{al}^{13}(\kappa=0.497)$ and Cook et $\mathrm{al}^{6}(\kappa=$ 0.696), also presented MetS according to the criteria proposed by Duncan et al, ${ }^{8}$ RodriguezMoran et $\mathrm{al}^{12}$ and Cruz and Goran. ${ }^{11} 95.2 \%$ of boys with MetS, as diagnosed with criteria by De Ferranti et al, ${ }^{9}$ were also diagnosed of Mets with the criteria by Duncan et al, ${ }^{8}$ RodriguezMoran et $\mathrm{al}^{12}$ and Cruz and Goran ${ }^{11}$ criteria $(\kappa=0.902)$. Good percentages of concordance 
were not observed between the cases diagnosed with the IDF criteria and each of the rest of the criteria.

In girls, those published by Duncan et $\mathrm{al}^{8}$ and Cruz and Goran ${ }^{11}$ were the criteria that diagnosed a higher number of MetS cases, 134 and 171, respectively. However, concordance values were not as high as those found for boys. Indeed, the highest kappa value observed in girls corresponded to the concordance of the criteria proposed by Weiss et $\mathrm{al}^{7}$ and Viner et $\mathrm{al},{ }^{13}$ and was 0.814 . All girls diagnosed of Mets with the criteria of Cook et $\mathrm{al}^{6}(\kappa=0.532)$, Weiss et $\mathrm{al}^{7}(\kappa=0.188)$, Viner et $\mathrm{al}^{13}(\kappa=0.217)$ and Rodriguez-Moran et $\mathrm{al}^{12}(\kappa=0.727)$, also presented MetS according to the criteria proposed by Duncan et al. ${ }^{8}$ In this line, all girls diagnosed of MetS with the criteria proposed by Weiss et $\mathrm{al}^{7}(\kappa=0.137)$, Viner et $\mathrm{al}^{13}(\kappa=0.159)$ and Rodriguez-Moran et $\mathrm{al}^{12}(\kappa=0.577)$ criteria were also diagnosed of Mets with the criteria by Cruz and Goran. ${ }^{11}$

\section{Discussion}

In the present study, we had the possibility for the first time to contrast the degree of agreement among eight diagnostic criteria to define MetS in boys and girls. The main findings of this study were the low degree of concordance observed between the IDF with the remaining diagnostic criteria, and a great agreement among the diagnostic criteria of Duncan et al, Rodriguez-Moran et al. and Cruz and Goran. To our knowledge, this is the first study of analyzing the concordance between eight different criteria for diagnosing metabolic syndrome in adolescents.

Our results show significantly lower values of WC, body weight and SBP in girls, along with significantly higher fat content in girls compared to boys. These differences among boys and girls could be explained, in part, by the variations in the body composition of the human species at that age, in particular due to a higher fat content in girls. ${ }^{26}$ 
With regard to the MetS components, in boys the highest mean values for WC, HDL-c, SBP and DBP were found after applying the criteria proposed by the IDF; in girls, applying these same criteria, higher mean values were also obtained for WC, SBP and DBP. These results partially differ from those obtained in other studies, such as the one developed by PeñaEspinoza et $a 1,{ }^{27}$ with a Mexican adolescent population, who found higher WC and HDL-c values, when the criteria proposed by Ferranti et $\mathrm{al}^{9}$ were used. In our study, the lowest mean values for WC, HDL-c and SBP were found in boys after applying the criteria of Cook et al ${ }^{6}$ and Viner et al, ${ }^{13}$ while in girls the lowest mean values for WC, SBP and DBP were found after applying the criteria of Cook et al, ${ }^{6}$ followed by the lowest HDL-c values after applying the criteria of Weiss et al. ${ }^{7}$ These results partially differ from those reported by Peña-Espinoza et $a{ }^{27}$ who regardless of sex obtained lower WC and HDL-c values when using the criteria proposed by Weiss et al. ${ }^{7}$ On the other hand, in our study, after applying the criteria of Viner et al, ${ }^{13}$ the highest mean levels of glucose and triglycerides were obtained in boys, while the lowest were found applying the criteria proposed by the IDF. These results differ from those observed by Reuter et al, ${ }^{19}$ who in their study with an adolescent population from 10 to 17 years of age in southern Brazil found lower mean glucose levels when applying the criteria of Cook et $\mathrm{al}^{6}$ and Ferranti et al, ${ }^{9}$ regardless of sex. These differences observed in the values for components of MetS with other authors might be explained by the variability in the ethnicity of the participants or the distinct number of participants diagnosed by the different diagnostic criteria.

On the other hand, our results show a high variability in the prevalence of MetS between both sexes according to the different criteria used. In boys, the prevalence ranges between $5.5 \%$ using the criteria of Viner et $\mathrm{al}^{13}$ and $14.9 \%$ applying the criteria of Duncan et al, ${ }^{8}$ RodriguezMoran et $\mathrm{al}^{12}$ and Cruz and Goran. ${ }^{11}$ In girls, a maximum prevalence of $32.6 \%$ was observed after applying the criteria of Cruz and Goran ${ }^{11}$ and $3.4 \%$ when the criteria established by 
Weiss et $\mathrm{al}^{7}$ are applied. According to Valdés-Villalpando et $\mathrm{al}^{28}$ these differences can be explained at the different cut-off points established in each criterion to assess body composition by means of WC or BMI using both percentiles and Z-scores, together with different criteria for dyslipidemia values for TG and HDL-c, using cut-off points in percentiles or $\mathrm{mg} / \mathrm{dL}$, as well as different cut-off points to define blood pressure levels. According to Weihe et $\mathrm{al},{ }^{29}$ this great variability justifies the urgent need to validate criteria to allow uniformity for the diagnosis of MetS in the adolescent population. Our results differ from those described by Reuter et al ${ }^{19}$ with Brazilian adolescents, in which they found a MetS prevalence of $1.9,5.0$ and $2.1 \%$ using the criteria of Cook et al, ${ }^{6}$ Ferranti et $\mathrm{al}^{9}$ and the IDF. Other international studies have shown dissimilar prevalences according to the diagnostic criteria used. For instance, Kim et $\mathrm{al}^{30}{ }^{30}$ in a representative study of the Korean adolescent population, obtained a MetS prevalence of $2.1 \%$ using the criteria defined by the National Cholesterol Education Program, Adult Treatment Panel III and IDF. Using the same criteria, in the study by Galera-Martínez et al, ${ }^{31}$ which was carried out with adolescents from Southern Spain, a prevalence of MetS of 3.8\% was reported. Another study developed in Turkey found a prevalence of MetS of $6.3 \%$ among adolescents using the criteria proposed by the IDF. ${ }^{32}$ Therefore, a great variability in the prevalence of MetS in adolescents is observed, depending on the diagnostic criteria used and their cut-off points. Taking into account that the best prevention and treatment of MetS depends on an early diagnosis, the choice of criteria to diagnose MetS in adolescents can compromise the clinical care of these subjects.

Regarding the degree of agreement between the different criteria applied for the diagnosis of MetS, the IDF criteria showed the lowest agreement in both boys and girls with the other criteria studied $(\kappa<0.550)$. These results are similar to the findings reported by Reuter et $\mathrm{al}^{19}$ and Agudelo et $\mathrm{a}^{33}$ who showed kappa values of 0.532 and 0.390 between the IDF vs Cook et $\mathrm{al}^{6}$ criteria, and 0.382 and 0.14 between the IDF vs de Ferranti et $\mathrm{al}^{9}$ criteria, respectively. 
Tavares Giannini et $\mathrm{al}^{34}$ also reported confirmed a low kappa value $(\kappa=0.48)$ for the agreement between the IDF and Ferranti et $\mathrm{al}^{9}$ criteria. However, the study carried out by Guilherme et $\mathrm{al}^{4}$ in Brazilian adolescents reported good agreement between the IDF criteria with the criteria proposed by Cook et $\mathrm{al}^{6}$ and Ferranti et $a{ }^{9}{ }^{9} \kappa=0.950$ and $\kappa=0.670$, respectively. This variability on the degree of agreement in the aforementioned studies was also observed in the study by Peña-Espinoza et al, ${ }^{27}$ where kappa values were 0.700 and 0.353 between the IDF criteria and the criteria of Cook et $\mathrm{al}^{6}$ and De Ferranti et al, ${ }^{9}$ respectively.

In boys, the criteria proposed by Duncan et al, ${ }^{8}$ Rodriguez-Moran et $\mathrm{al}^{12}$ and Cruz and Goran ${ }^{11}$ were very concordant among each other, with kappa values above 0.999 . However, in girls concordance values between these criteria were good but not as high as those found for boys. In this regard, the study carried out by Mirmiran et $\mathrm{al}^{35}$ showed a kappa value of 0.359 between the Duncan et $\mathrm{al}^{8}$ and Cruz and Goran ${ }^{11}$ criteria, which differs from our results. Our findings also showed a great concordance between the criteria proposed by Duncan et al, ${ }^{8}$ Rodriguez-Moran et al. ${ }^{12}$ and Cruz and Goran ${ }^{11}$ and the criteria of De Ferranti et $\mathrm{al}^{9}(\kappa=$ 0.902) in boys. These results partially differ from those obtained by Mirmiran et al, ${ }^{35}$ who in adolescent population and regardless of sex, reported kappa values of 0.616 and 0.178 between the criteria proposed by de Ferranti et $\mathrm{al}^{9}$ and Duncan et $\mathrm{al}^{8}$ and Cruz and Goran ${ }^{11}$ respectively. Furthermore, Seo et $\mathrm{al}^{36}$ reported a kappa value of 0.407 in the Korean adolescent population between the criteria of Cruz and Goran ${ }^{11}$ and Ferranti et al, ${ }^{9}$ regardless of sex.

The present study has some strengths and limitations. This study is the first, to our knowledge, that was employed eight different criteria for the diagnosis of MetS in Spanish adolescents and that includes an analysis of concordance between the different diagnostic criteria for MetS. In addition, we would like to emphasize the usefulness of the large sample size, which contributes to obtaining solid results that will improve comparability in future 
studies. In addition, all participants were of the same geographical region, with similar culture, lifestyle and eating habits, making the sample more homogeneous. The most important limitation of the present study is its cross-sectional design.

\section{Conclusions}

Our results showed a great concordance between the criteria proposed by Duncan et $a{ }^{8}{ }^{8}$ Rodríguez-Moran et $\mathrm{al}^{12}$ and Cruz and Goran, ${ }^{11}$ and also between these criteria and the criteria proposed by de Ferranti et al. ${ }^{9}$ We also report a lower degree of agreement between the IDF criteria and the remaining 7 criteria used to diagnose MetS. However, our results differ from that reported by previous studies with similar characteristics, highlighting the differences between the different criteria for diagnosing MetS. The discrepancies observed in the agreement among the eight criteria employed in our study, and also in comparison with other authors, suggest the need to validate criteria that allow a uniformity in the diagnosis of MetS in adolescents, which is crucial for the clinical and public health authorities in the management of this important public health problem.

\section{Acknowledgements}

The authors are grateful to schools, parents, and guardians as well as to participant students for their collaboration in the development of this study.

\section{Disclosures}

No conflict of interest, financial or otherwise is declared by the authors.

Author contributionsEGJ and JSP conceived and designed the study. AFA collected and analyzed the data. JSR interpreted the data. EGJ, JSP and AFA drafted the manuscript. All authors have revised and approved the submitted manuscript. 


\section{References}

1. Martin CL, Kane JB, Miles GL, Aiello AE, Harris KM. Neighborhood disadvantage across the transition from adolescence to adulthood and risk of metabolic syndrome. Health Place. 2019;57:131-138.

2. Morrison JA, Friedman LA, Gray-Mcguire C. Metabolic syndrome in childhood predicts adult cardiovascular disease 25 years later: the Princeton Lipid Research Clinics Follow-up Study. Pediatrics. 2007;120:340-345.

3. Kaur J. A comprehensive review on metabolic syndrome. Cardiol Res Pract. 2014;1-21. https://doi.org/10.1155/2014/943162

4. Guilherme FR, Nascimento MAD, Molena-Fernandes CA, et al. Comparison of different criteria in the prevalence of metabolic syndrome in students from Paranavaí, Paraná. Rev Paul Pediatr. 2019;37(3):332-337.

5. National Institutes of Health/National Heart, Lung, and Blood Institute. Third Report of the National Cholesterol Education Program (NCEP). In Expert Panel on Detection, Evaluation, and Treatment of High Blood Cholesterol in Adults (Adult Treatment Panel III); Final Report; National Institutes of Health: Bethesda, MD, USA, 2002.

6. Cook S, Weitzman M, Auinger P, Nguyen M, Dietz WH. Prevalence of a metabolic syndrome phenotype in adolescents: Findings from the third National Health and Nutrition Examination Survey, 1988-1994. Arch Pediatr Adolesc Med. 2003;157:821-827.

7. Weiss R, Dziura J, Burgert TS, et al. Obesity and the metabolic syndrome in children and adolescents. N Engl J Med. 2004;350:2362-2374.

8. Duncan GE, Li SM, Zhou XH. Prevalence and trends of a metabolic syndrome phenotype among U.S. adolescents, 1999-2000. Diabetes Care. 2004;27:2438-2443. 
9. De Ferranti SD, Gauvreau K, Ludwig DS, Neufeld EJ, Newburger JW, Rifai N. Prevalence of the metabolic syndrome in American adolescents: Findings from the Third National Health and Nutrition Examination Survey. Circulation. 2004;110:2494-2497.

10. Zimmet P, Alberti KG, Kaufman F, et al. The metabolic syndrome in children and adolescents_An IDF consensus report. Pediatr Diabetes. 2007;8:299-306.

11. Cruz ML, Goran MI. The metabolic syndrome in children and adolescents. Curr Diabetes Rep. 2004;4:53-62.

12. Rodríguez M, Salazar B, Violante R, Guerrero F. Metabolic syndrome among children and adolescents aged 10-18 years. Diabetes Care. 2004; 27: 2516-2517.

13. Viner RM, Segal TY, Lichtarowicz-Krynska E, Hindmarsh P. Prevalence of the insulin resistance syndrome in obesity. Arch Dis Child. 2005;90:10-14.

14. Alberti KG, Zimmet PZ. Definition, diagnosis and classification of diabetes mellitus and its complications. Part 1: Diagnosis and classification of diabetes mellitus provisional report of a WHO consultation. Diabetes Med. 1998;15:539-553.

15. Costa RF, Santos NS, Goldraich NP, Barski TF, Andrade KS, Kruel LF. Metabolic syndrome in obese adolescents: a comparison of three different diagnostic criteria. J Pediatr (Rio J). 2012; 88:303-309.

16. Sewaybricker LE, Antonio MA, Mendes RT, Barros Filho AA, Zambon MP. Metabolic syndrome in obese adolescents: what is enough? Rev Assoc Med Bras. 2013;59:64-71.

17. Braga-Tavares H, Fonseca H. Prevalence of metabolic syndrome in a Portuguese obese adolescent population according to three different definitions. Eur J Pediatr. 2010;169:935-940.

18. Sangun Ö, Dündar B, Köşker M, Pirgon Ö, Dündar N. Prevalence of metabolic syndrome in obese children and adolescents using three different criteria and evaluation of risk factors. J Clin Res Pediatr Endocrinol. 2011;3:70-76. 
19. Reuter CP, Burgos MS, Barbian CD, Renner JDP, Franke SIR, de Mello ED.

Comparison between different criteria for metabolic syndrome in schoolchildren from southern Brazil. Eur J Pediatr. 2018;177(10):1471-1477.

20. Simera I, Moher D, Hoey J, Schulz KF, Altman DG. A catalogue of reporting guidelines for health research. Eur J Clin Invest. 2010;40(1):35-53.

21. Marfell-Jones M, Olds T, Stewart A. International Standards for Anthropometric Assessment. Potchefstroom, South Africa: ISAK; 2006.

22. Brook CGD. Determination of body composition of children from skinfold measurements. Arch Dis Child. 1971,46,182-184.

23. Siri WE. Body composition from fluid spaces and density: Analysis of methods. In Techniques for Measuring Body Composition; Brozeck, J., Henschel, A., Eds.; National Academies Sciences National Research Council: Washington, DC, USA, 1961.

24. Matthews D, Hosker J, Rudenski A, Naylor B, Treacher D, Turner R. Homeostasis model assessment: insulin resistance and B-cell function from fasting plasma glucose and insulin concentrations in man. Diabetologia. 1985; 28:412-419.

25. Pickering TG, Hall JE, Appel LJ, et al. Recommendations for blood pressure measurement in humans and experimental animals, part 1: blood pressure measurement in humans: a statement for professionals from the Subcommittee of Professional and Public Education of the American Heart Association Council on High Blood Pressure Research. Hypertension. 2005;45:142-161.

26. Nasreddine L, Naja F, Tabet M, et al. Obesity is associated with insulin resistance and components of the metabolic syndrome in Lebanese adolescents. Ann Hum Biol. 2012;39:122-128. 
27. Peña-Espinoza BI, Granados-Silvestre MA, Sánchez-Pozos K, Ortiz-López MG, Menjivar M. Metabolic syndrome in Mexican children: Low effectiveness of diagnostic definitions. Endocrinol Diabetes Nutr. 2017;64(7):369-376.

28. Valdés-Villapardo Y, Campuzano J, Sánchez Zamorano LM, et al. Estudio de validación de cuatro diferentes criterios para el diagnóstico de síndrome metabólico en población infantil. Rev Univ Ind Santander Salud. 2018;50(2):126-135.

29. Weihe P, Weihrauch-Blüher S. Metabolic Syndrome in Children and Adolescents: Diagnostic Criteria, Therapeutic Options and Perspectives. Current Obesity Reports. $2019 ; 8: 472-479$.

30. Kim S, So WY. Prevalence of metabolic syndrome among Korean adolescents according to the National Cholesterol Education Program, Adult Treatment Panel III and International Diabetes Federation. Nutrients. 2016;8:1-9.

31. Galera-Martínez R, García-García E, Vázquez-López MA, et al. Prevalence of metabolic syndrome among adolescents in a city in the Mediterranean area: comparison of two definitions. Nutr Hosp. 2015;32(2):627-633.

32. Inanc BB. Metabolic syndrome in school children in Mardin, South-eastern of Turkey. Eurasian J Med. 2014;46:156-163.

33. Agudelo GM, Bedoya G, Estrada A, Patiño FA, Muñoz AM, Velásquez CM. Variations in the prevalence of metabolic syndrome in adolescents according to different criteria used for diagnosis: which definition should be chosen for this age group? Metab Syndr Relat Disord. 2014;12(4):202-209.

34. Tavares Giannini D, Caetano Kuschnir MC, Szklo M. Metabolic syndrome in overweight and obese adolescents: a comparison of two different diagnostic criteria. Ann Nutr Metab. 2014;64(1):71-79. 
35. Mirmiran P, Sherafat-Kazemzadeh R, Farahani SJ, et al. Performance of different definitions of metabolic syndrome for children and adolescents in a 6-year follow-up: Tehran Lipid and Glucose Study (TLGS). Diabetes Res Clin Pract. 2010;89(3):327-333

36. Seo SJ, Lee HY, Lee SW. The prevalence of the metabolic syndrome in Korean children and adolescents: comparisons of the criteria of Cook et al., Cruz and Goran, and Ferranti et al. Yonsei Med J. 2008;49(4):563-572

37. Simera I, Moher D, Hoey J, Schulz KF, Altman DG. A catalogue of reporting guidelines for health research. Eur J Clin Invest. 2010;40(1):35-53.

\section{Figure Legend}

Figure 1. Flow diagram of the recruitment progress.

Figure 2. Kappa values for agreement for the diagnosis of metabolic syndrome in adolescents according to the eight criteria employ 
Table Suplemmentary. Diagnostic criteria for the MetS in adolescents.

\begin{tabular}{|c|c|c|c|c|c|c|c|c|}
\hline & IDF & Cook & de Ferranti & Weiss & Viner & Duncan & $\begin{array}{c}\text { Rodríguez- } \\
\text { Moran }\end{array}$ & $\begin{array}{c}\text { Cruz \& } \\
\text { Goran }\end{array}$ \\
\hline Age (years) & $10-16$ & $12-19$ & $\geq 12$ & $4-20$ & $2-18$ & $12-19$ & $10-18$ & $8-13$ \\
\hline $\begin{array}{l}\text { Number of } \\
\text { components }\end{array}$ & $\begin{array}{c}\text { Obesity } \\
+2 \text { components }\end{array}$ & $\geq 3$ & $\geq 3$ & $\geq 3$ & $\geq 4$ & $\geq 3$ & $\geq 3$ & $\geq 3$ \\
\hline Obesity & $\begin{array}{l}\mathrm{WC}>90 \\
\text { percentile }\end{array}$ & $\begin{array}{l}\mathrm{WC}>90 \\
\text { percentile }\end{array}$ & $\begin{array}{l}\mathrm{WC}>75 \\
\text { percentile }\end{array}$ & $\begin{array}{c}\text { BMI z-score } \geq \\
2\end{array}$ & $\begin{array}{l}\mathrm{BMI} \geq 95 \\
\text { percentile }\end{array}$ & $\begin{array}{l}\mathrm{WC} \geq 90 \\
\text { percentile }\end{array}$ & $\begin{array}{l}\mathrm{WC} \geq 90 \\
\text { percentile }\end{array}$ & $\begin{array}{l}\mathrm{WC} \geq 90 \\
\text { percentile }\end{array}$ \\
\hline $\begin{array}{l}\text { Glucose } \\
(\mathrm{mg} / \mathrm{dL})\end{array}$ & $\geq 100$ & $\geq 110$ & $\geq 110$ & $\geq 140$ & $\geq 110$ & $\geq 110$ & $\geq 110$ & $>100$ \\
\hline $\mathrm{TG}(\mathrm{mg} / \mathrm{dL})$ & $\geq 150$ & $\geq 110$ & $\geq 100$ & $\begin{array}{c}c>95 \\
\text { percentile }\end{array}$ & $\geq 150$ & $\geq 110$ & $\begin{array}{c}\geq 90 \\
\text { percentile }\end{array}$ & $\geq 90$ percentile \\
\hline $\begin{array}{l}\text { HDL-cholesterol } \\
(\mathrm{mg} / \mathrm{dL})\end{array}$ & $\leq 40$ & $\leq 40$ & $\begin{array}{l}<50 \text { girls } \\
<45 \text { boys }\end{array}$ & $\begin{array}{c}<5 \\
\text { percentile }\end{array}$ & $\leq 35$ & $<40$ & - & $\begin{array}{c}\quad<10 \\
\text { percentile }\end{array}$ \\
\hline $\begin{array}{l}\text { SBP } \\
(\mathrm{mmHg})\end{array}$ & $\geq 130$ & $\begin{array}{c}>90 \\
\text { percentile }\end{array}$ & $\begin{array}{c}>90 \\
\text { percentile }\end{array}$ & $\begin{array}{c}>>95 \\
\text { percentile }\end{array}$ & $\begin{array}{c}>95 \\
\text { percentile }\end{array}$ & $\begin{array}{c}\geq 90 \\
\text { percentile }\end{array}$ & $\begin{array}{c}\geq 90 \\
\text { percentile }\end{array}$ & $\begin{array}{c}\quad \geq 90 \\
\text { percentile }\end{array}$ \\
\hline $\begin{array}{l}\text { DBP } \\
(\mathrm{mmHg})\end{array}$ & $\geq 85$ & - & - & - & - & - & - & - \\
\hline
\end{tabular}

IDF, International Diabetes Federation; TG, triglycerides; HDL, high-density lipoprotein; SBP, systolic blood pressure, DBP, diastolic blood pressure, WC, waist circumference; BMI, body mass index. 
Table 1. Characteristics of participants.

\begin{tabular}{lcccc}
\hline & \multicolumn{2}{c}{$\begin{array}{c}\text { Boys } \\
(\mathrm{n}=456)\end{array}$} & $\begin{array}{c}\text { Girls } \\
(\mathrm{n}=525)\end{array}$ \\
\hline & Mean & SD & Mean & SD \\
\hline Age (y) & 13.2 & 1.2 & 13.3 & 1.2 \\
\hline Weight (kg) & 57.1 & 14.1 & $53.1^{* * *}$ & 11.0 \\
\hline Fat (\%) & 27.3 & 8.3 & $29.6 * * *$ & 7.8 \\
\hline BMI (kg/m²) & 21.5 & 4.0 & 21.1 & 3.6 \\
\hline WC (cm) & 73.7 & 11.8 & $71.3 * * *$ & 9.6 \\
\hline Glucose (mg/dL) & 86.2 & 31.2 & 85.2 & 28.7 \\
\hline Triglycerides (mg/dL) & 129.2 & 59.3 & 125.0 & 46.2 \\
\hline Cholesterol (mg/dL) & 81.8 & 17.3 & 81.4 & 15.7 \\
\hline LDL-c (mg/dL) & 93.4 & 23.6 & 92.9 & 22.5 \\
\hline HDL-c (mg/dL) & 40.1 & 2.8 & 40.0 & 3.1 \\
\hline SBP (mmHg) & 119.6 & 15.7 & $116.9 * *$ & 15.1 \\
\hline DBP (mmHg) & 64.5 & 9.2 & 63.9 & 8.8 \\
\hline Insulina (mU/mL) & 21.0 & 10.2 & 20.2 & 9.0 \\
\hline HOMA-IR & 4.5 & 2.9 & 4.3 & 3.1 \\
\hline
\end{tabular}

Fat (\%), body fat percentage; BMI, body mass index; WC, waist circumference; TG, triglycerides; LDL-c, low-density lipoprotein cholesterol; HDL-c, high-density lipoprotein cholesterol; SBP, systolic blood pressure, DBP, diastolic blood pressure, HOMA-IR, homeostatic model assessment of insulin resistance. Differences between means were assessed by an unpaired Student's t-test. **, p $<0.05$; *** ${ }^{* *}<0.001$. 
Table 2. Values for components of MetS in subjects with MetS according to diagnostic criteria.

\begin{tabular}{|c|c|c|c|c|c|c|c|c|c|c|c|c|c|c|c|c|}
\hline & \multicolumn{2}{|c|}{ IDF } & \multicolumn{2}{|c|}{ Cook } & \multicolumn{2}{|c|}{ De Ferranti } & \multicolumn{2}{|c|}{ Weiss } & \multicolumn{2}{|c|}{ Viner } & \multicolumn{2}{|c|}{ Duncan } & \multicolumn{2}{|c|}{$\begin{array}{l}\text { Rodríguez- } \\
\text { Moran }\end{array}$} & \multicolumn{2}{|c|}{$\begin{array}{c}\text { Cruz \& } \\
\text { Goran }\end{array}$} \\
\hline & Mean & SD & Mean & SD & Mean & SD & Mean & SD & Mean & SD & Mean & SD & Mean & SD & Mean & SD \\
\hline \multicolumn{17}{|l|}{ Boys } \\
\hline MS (number) & \multicolumn{2}{|c|}{41} & \multicolumn{2}{|c|}{39} & \multicolumn{2}{|c|}{63} & \multicolumn{2}{|c|}{32} & \multicolumn{2}{|c|}{25} & \multicolumn{2}{|c|}{68} & \multicolumn{2}{|c|}{68} & \multicolumn{2}{|c|}{68} \\
\hline $\mathrm{WC}(\mathrm{cm})$ & $86.0^{\mathrm{a}}$ & 9.9 & $74.6^{\mathrm{b}}$ & 11.7 & $80.2^{\mathrm{ab}}$ & 12.7 & $76.9^{\mathrm{b}}$ & 14.0 & $77.8^{\mathrm{ab}}$ & 13.5 & $79.5^{\mathrm{ab}}$ & 12.4 & $79.5^{\mathrm{ab}}$ & 12.4 & $79.5^{\mathrm{ab}}$ & 12.4 \\
\hline Glucose (mg/dL) & $128.4^{\mathrm{a}}$ & 53.5 & $172.9^{b}$ & 47.4 & $139.5^{\mathrm{a}}$ & 56.9 & $191.4^{\mathrm{b}}$ & 27.7 & $193.7^{\mathrm{b}}$ & 24.4 & $136.0^{\mathrm{a}}$ & 56.2 & $136.0^{\mathrm{a}}$ & 56.2 & $136.0^{\mathrm{a}}$ & 56.2 \\
\hline Triglycerides (mg/dL) & $193.0^{\mathrm{a}}$ & 120.1 & $257.9^{\mathrm{a}}$ & 146.4 & $210.1^{\mathrm{ac}}$ & 133.9 & $295.0^{\mathrm{bc}}$ & 143.9 & $338.9^{b}$ & 132.5 & $204.0^{\mathrm{a}}$ & 130.6 & $204.0^{\mathrm{a}}$ & 130.6 & $204.0^{\mathrm{a}}$ & 130.6 \\
\hline HDL-c (mg/dL) & $35.7^{\mathrm{a}}$ & 3.4 & $33.1^{\mathrm{bc}}$ & 2.2 & $35.0^{\mathrm{a}}$ & 3.4 & $32.3^{c}$ & 1.6 & $32.4^{\mathrm{c}}$ & 1.8 & $34.9^{\mathrm{ab}}$ & 3.2 & $34.9^{\mathrm{ab}}$ & 3.2 & $34.9^{\mathrm{ab}}$ & 3.2 \\
\hline SBP (mmHg) & $137.2^{\mathrm{a}}$ & 14.7 & $121.6^{\mathrm{b}}$ & 17.0 & $123.5^{\mathrm{b}}$ & 17.3 & $122.9^{\mathrm{b}}$ & 17.9 & $123.4^{\mathrm{b}}$ & 18.8 & $124.0^{\mathrm{b}}$ & 16.6 & $124.0^{\mathrm{b}}$ & 16.6 & $124.0^{\mathrm{b}}$ & 16.6 \\
\hline DBP mmHg) & $74.1^{\mathrm{a}}$ & 11.4 & $64.6^{\mathrm{b}}$ & 8.6 & $65.5^{\mathrm{b}}$ & 9.0 & $65.1^{\mathrm{b}}$ & 9.0 & $63.9^{\mathrm{b}}$ & 9.2 & $66.3^{\mathrm{b}}$ & 8.7 & $66.3^{\mathrm{b}}$ & 8.7 & $66.3^{\mathrm{b}}$ & 8.7 \\
\hline
\end{tabular}

\section{Girls}

\begin{tabular}{|c|c|c|c|c|c|c|c|c|c|c|c|c|c|c|c|c|}
\hline \multirow{2}{*}{$\begin{array}{l}\text { MS (number) } \\
\text { WC (cm) }\end{array}$} & \multicolumn{2}{|c|}{32} & \multicolumn{2}{|c|}{58} & \multicolumn{2}{|c|}{97} & \multicolumn{2}{|c|}{18} & \multicolumn{2}{|c|}{21} & \multicolumn{2}{|c|}{134} & \multicolumn{2}{|c|}{86} & \multicolumn{2}{|c|}{171} \\
\hline & $83.2^{\mathrm{a}}$ & 7.5 & $70.5^{b}$ & 10.4 & $75.2^{\mathrm{bc}}$ & 10.3 & $73.7^{\mathrm{bc}}$ & 14.8 & $75.5^{\mathrm{ab}}$ & 13.3 & $73.6^{\mathrm{b}}$ & 9.1 & $79.5^{\mathrm{ac}}$ & 12.4 & $73.7^{\mathrm{b}}$ & 9.5 \\
\hline Glucose (mg/dL) & $131.9^{\mathrm{abc}}$ & 52.2 & $148.3^{\mathrm{b}}$ & 51.8 & $121.1^{\mathrm{a}}$ & 52.3 & $194.4^{\mathrm{d}}$ & 7.1 & $188.2^{\mathrm{d}}$ & 22.5 & $110.0^{c}$ & 48.2 & $139.2^{\mathrm{ab}}$ & 50.7 & 104.5 & 43.49 \\
\hline Triglycerides (mg/dL) & $196.2^{\mathrm{ab}}$ & 120.9 & $191.6^{\mathrm{ab}}$ & 114.9 & $164.5^{\mathrm{ab}}$ & 98.1 & $329.8^{c}$ & 121.9 & $312.9^{c}$ & 128.1 & $151.9^{\mathrm{a}}$ & 85.9 & $204.0^{\mathrm{b}}$ & 130.6 & $145.5^{\mathrm{a}}$ & 77.0 \\
\hline HDL-c (mg/dL) & $35.3^{\mathrm{ab}}$ & 2.6 & $33.7^{\mathrm{a}}$ & 4.5 & $36.1^{\mathrm{b}}$ & 4.8 & $32.8^{\mathrm{a}}$ & 1.3 & $33.1^{\mathrm{a}}$ & 1.3 & $37.2^{c}$ & 4.6 & $34.9^{\mathrm{a}}$ & 3.2 & $38.0^{c}$ & 4.3 \\
\hline SBP (mmHg) & $132.3^{\mathrm{a}}$ & 10.2 & $113.4^{\mathrm{b}}$ & 17.1 & $117.7^{\mathrm{bc}}$ & 17.0 & $116.4^{\mathrm{bc}}$ & $20.8^{\mathrm{a}}$ & $118.8^{\mathrm{ab}}$ & 19.5 & $117.2^{\mathrm{b}}$ & 15.5 & $124.0^{\mathrm{ac}}$ & 16.6 & $117.5^{\mathrm{b}}$ & 15.3 \\
\hline DBP mmHg) & $70.7^{\mathrm{a}}$ & 8.8 & $62.1^{\mathrm{a}}$ & 8.8 & $62.6^{\mathrm{a}}$ & 9.5 & $64.4^{\mathrm{a}}$ & 10.2 & $64.4^{\mathrm{a}}$ & 10.1 & $63.0^{\mathrm{a}}$ & 9.0 & $66.3^{\mathrm{a}}$ & 8.7 & $63.7^{\mathrm{a}}$ & 8.9 \\
\hline
\end{tabular}

WC, waist circumference; HDL-c, high-density lipoprotein cholesterol; SBP, systolic blood pressure, DBP, diastolic blood pressure. Differences between means that share a letter are not statistically significant $(\mathrm{p}<0.05)$. 
Table 3. Prevalence (\%) of components of MetS according to the different diagnostic criteria in adolescents.

\begin{tabular}{lcccccc}
\hline & $\begin{array}{c}\text { Abdominal } \\
\text { Obesity }\end{array}$ & Hiperglycemia & Hypertriglyceridemia & Low HDL-c & Hypertension & MetS \\
\hline Boys & & & & & & \\
\hline IDF & 48.0 & 6.8 & 3.9 & 18.0 & 39.5 & 9.0 \\
Cook & 48.0 & 6.8 & 99.3 & 18.0 & 17.1 & 8.6 \\
De Ferranti & 24.3 & 6.8 & 100.0 & 18.0 & 17.1 & 13.8 \\
Weiss & 5.5 & 6.8 & 11.0 & 13.6 & 1.3 & 7.0 \\
Viner & 48.0 & 6.8 & 3.9 & 18.0 & 1.3 & 5.5 \\
Duncan & 33.8 & 6.8 & 99.3 & 18.0 & 17.1 & 14.9 \\
Rodriguez-Moran & 33.8 & 6.8 & 99.8 & 18.0 & 17.1 & 14.9 \\
Cruz \& Goran & 33.8 & 6.8 & 99.8 & 18.0 & 17.1 & 14.9 \\
\hline Girls & & & & & & \\
\hline IDF & 37.0 & 6.3 & 2.7 & 18.1 & 34.7 & 6.1 \\
Cook & 37.0 & 6.3 & 99.0 & 18.1 & 40.8 & 11.0 \\
De Ferranti & 28.0 & 6.3 & 100.0 & 18.1 & 40.8 & 18.5 \\
Weiss & 4.6 & 6.3 & 3.2 & 18.1 & 3.0 & 3.4 \\
Viner & 37.0 & 6.3 & 2.7 & 18.1 & 3.0 & 4.0 \\
Duncan & 55.2 & 6.3 & 99.0 & 18.1 & 40.8 & 25.5 \\
Rodriguez-Moran & 55.2 & 6.3 & 28.6 & 18.1 & 40.8 & 16.4 \\
Cruz \& Goran & 55.2 & 6.3 & 28.6 & 18.1 & 40.8 & 32.6 \\
\hline
\end{tabular}


Table 4. Number of concordant cases of boys with MetS according to Kappa after crossing diagnostic criteria.

\begin{tabular}{|c|c|c|c|c|c|c|c|c|}
\hline & IDF & Cook & $\begin{array}{c}\text { De } \\
\text { Ferranti }\end{array}$ & Weiss & Viner & Duncan & $\begin{array}{l}\text { Rodriguez- } \\
\text { Moran }\end{array}$ & $\begin{array}{c}\text { Cruz \& } \\
\text { Goran }\end{array}$ \\
\hline IDF & 41 & & & & & & & \\
\hline Cook & 19 & 39 & & & & & & \\
\hline De Ferranti & 29 & 39 & 63 & & & & & \\
\hline Weiss & 18 & 30 & 32 & 32 & & & & \\
\hline Viner & 17 & 24 & 25 & 25 & 25 & & & \\
\hline Duncan & 31 & 39 & 60 & 32 & 25 & 68 & & \\
\hline Rodriguez-Moran & 31 & 39 & 60 & 32 & 25 & 68 & 68 & \\
\hline Cruz \& Goran & 31 & 39 & 60 & 32 & 25 & 68 & 68 & 68 \\
\hline
\end{tabular}


Table 5. Number of concordant cases of girls with MetS according to Kappa after crossing diagnostic criteria.

\begin{tabular}{|c|c|c|c|c|c|c|c|c|}
\hline & IDF & Cook & $\begin{array}{c}\text { De } \\
\text { Ferranti }\end{array}$ & Weiss & Viner & Duncan & $\begin{array}{c}\text { Rodriguez- } \\
\text { Moran }\end{array}$ & $\begin{array}{c}\text { Cruz \& } \\
\text { Goran }\end{array}$ \\
\hline IDF & 32 & & & & & & & \\
\hline Cook & 21 & 58 & & & & & & \\
\hline De Ferranti & 28 & 58 & 97 & & & & & \\
\hline Weiss & 9 & 18 & 18 & 18 & & & & \\
\hline Viner & 14 & 20 & 21 & 16 & 21 & & & \\
\hline Duncan & 29 & 58 & 92 & 18 & 21 & 134 & & \\
\hline Rodriguez-Moran & 29 & 56 & 70 & 18 & 21 & 86 & 86 & \\
\hline Cruz \& Goran & 30 & 56 & 90 & 18 & 21 & 130 & 86 & 171 \\
\hline
\end{tabular}




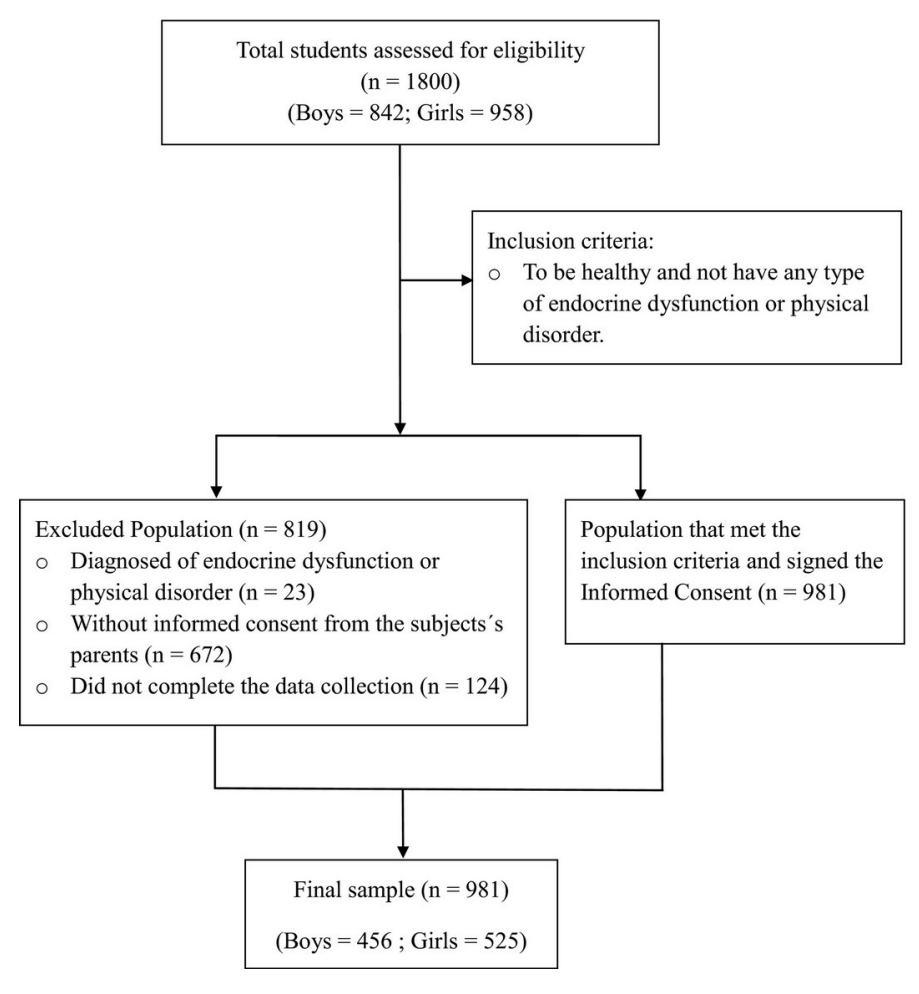




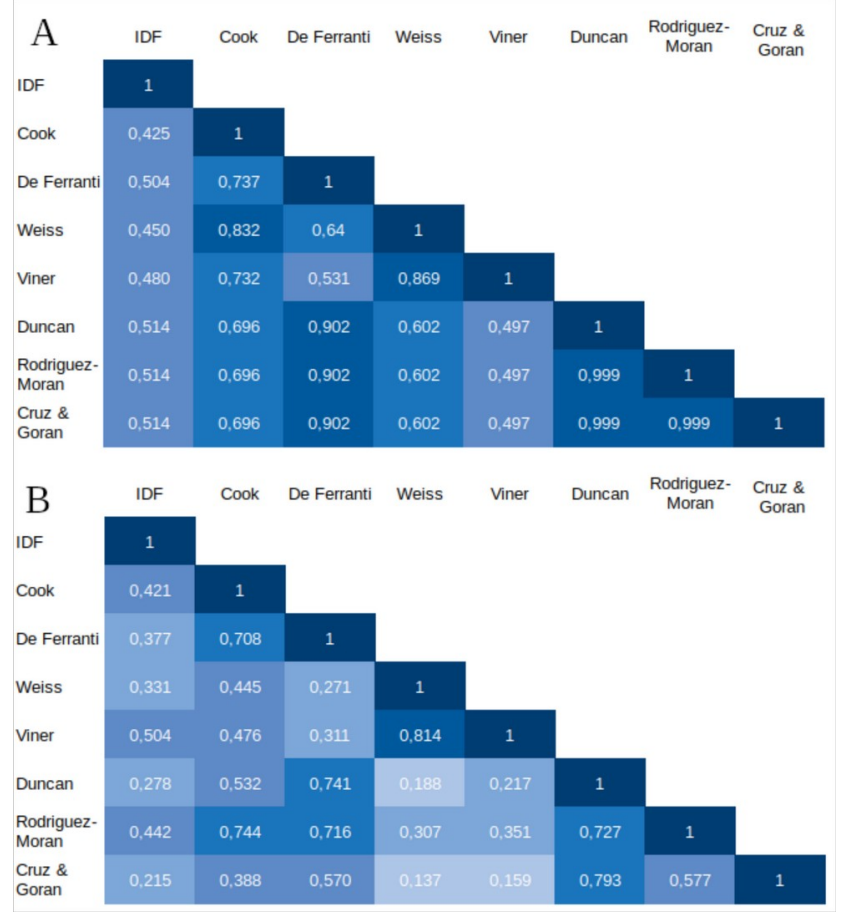

